\title{
SENSITIVITY AND SPECIFICITY OF ELECTROENCEPHALOGRAPHY (EEG) AMONG PATIENTS REFERRED TO AN ELECTROPHYSIOLOGY LAB IN BANGLADESH
}

\author{
CHOWDHURY AH ${ }^{1}, \mathrm{CHOWDHURY} \mathrm{RN}^{2}, \mathrm{KHAN} \mathrm{SU}^{3}$, GHOSE SK $^{4}$, WAZIB A ${ }^{5}$, ALAM I ${ }^{6}$,

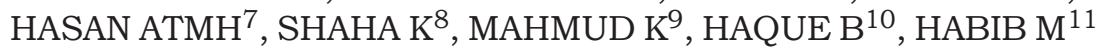

\begin{abstract}
Objective: To measure the changes in electro encephalogram (EEG) along with its sensitivity and specificity with clinical seizure among epilepsy patients referred to an electrophysiology lab in a tertiary care hospital of Bangladesh.

Methods: This retrospective chart review was carried out in the electrophysiology laboratory of Dhaka Medical College Hospital from January 2011 to December 2013, which included 1154 patients. EEG was obtained through scalp electrodes following international 10/20 system. Information regarding patients was collected from the laboratory register with the help of a checklist. The EEG findings and clinical seizure events were then compared.

Result: Among the 1154 patients, age varied from birth to 75 years. The mean age at presentation was $17 \pm 11.4$ years and most of the patients were less than 10 years old (44.4\%). The male predominated in our study (59.2\%). Clinically diagnosed seizure was present in 970 patients (84.1\%), among which Generalized tonic clonic seizure (GTCS) was the most common clinical type of seizure, followed by secondary generalized seizure in $19.4 \%(n=224)$ and focal seizure in $2 \%(n=30)$ patients and $6.8 \%(n=79)$ patients had pseudoseizure. Among the abnormal EEG (59\%), generalized epileptiform discharge was found in 29\%, whereas focal and secondary generalized discharge was found in 30\%. The most common site of origin of epileptiform discharge was temporal lobe (28.3\%). The overall sensitivity of EEG was 66\% (ranged from 62\% to 68\% with a confidence interval (CI) at 95\%) and specificity was 79\% (72$84 \%$ at $95 \%$ CI). The positive predictive value was 58\% (55-61\% at 95\% CI) and negative predictive value was $41 \%$ (38-44\% at 95\% CI).
\end{abstract}

Conclusion: Our study brings out the fact that EEG has a reasonable sensitivity and specificity as a diagnostic test and the superiority being the higher specificity of EEG.

Key words: Interictal EEG, generalized tonic clonic seizure (GTCS).

J Dhaka Med Coll. 2014; 23(2) : 215-222.

\section{Introduction:}

The first description of an epileptic crisis dates back to 3000 b.c. But the human electroencephalogram (EEG) was discovered by the German psychiatrist, Hans Berger, in 1929.
As Gibbs and his colleagues ${ }^{1}$ discovered the pattern of epileptic discharges in 1935, its potential applications in epilepsy rapidly became clear. EEG has been playing a central role in diagnosing and managing epilepsy, as

1. Dr. Ahmed Hossain Chowdhury, Assistant Professor, Department of Neurology, Dhaka Medical College \& Hospital, Dhaka.

2. Dr. Rajib Nayan Chowdhury, Assistant Professor, Department of Neurology, National Institute of Neurosciences \& Hospital, Dhaka.

3. Dr. Sharif Uddin Khan, Associate Professor, Department of Neurology, Dhaka Medical College \& Hospital, Dhaka.

4. Dr. Swapon Kumar Ghose, Associate Professor, Department of Neurology, Dhaka Medical College \& Hospital, Dhaka.

5. Dr. Amit Wazib, Consultant, Department of Neurology, Dhaka Medical College Hospital, Dhaka.

6. Dr. Iftikher Alam Consultant, Department of Neurology, Dhaka Medical College Hospital, Dhaka.

7. Dr. ATM Hasibul Hasan, MD student, Department of Neurology, Dhaka Medical College, Dhaka.

8. Dr. Kanol Shaha, Registrar, Department of Neurology, Dhaka Medical College Hospital, Dhaka.

9. Dr. Khurshid Mahmud, Associate Professor, Department of Physical Medicine, National Institute of Neuroscience (NINS), Dhaka

10. Dr. Badrul Haque, Associate Professor, Department of Neurology, Dhaka Medical College \& Hospital, Dhaka. 11. Prof. Mansur Habib, Professor, Department of Neurology, Dhaka Medical College Hospital, Dhaka.

Correspondence: Dr. ATM Hasibul Hasan, MD Student, Department of Neurology, Dhaka Medical College Hospital, Dhaka. Cell Phone: +8801763498663, Email: parag007us@gmail.com 
it is a convenient and relatively inexpensive way to demonstrate the physiological manifestations of abnormal cortical events that underlie epilepsy.

Epilepsy is often defined as the tendency to have recurrent unprovoked seizure, whilst a seizure is any clinical event caused by abnormal electrical discharge in the brain ${ }^{2}$. The incidence of epilepsy varies worldwide ${ }^{3}$ with a higher prevalence in developing countries $^{4-6}$. The life time prevalence of epilepsy also varies from 1.5 to 14 per 1000 population among different countries ${ }^{7-15}$. More than half of the 50 million people with epilepsy worldwide live in Asian countries. WHO estimated that there are 1.5-2 million people suffering from epilepsy in Bangladesh ${ }^{16}$.

Though scalp EEG has a number of limitations, it can help to determine the seizure types and epilepsy syndromes among patients with epilepsy. There is a significant association between the interpreted presence of epileptiform discharges (EDs) and a subsequent seizure ${ }^{17,18}$. Interestingly enough, the frequency of reported EEG abnormalities in patients with seizures varies widely between studies $(29-69 \%)^{19-21}$ and when are repeated in the same subject, the results are often inconsistent ${ }^{22,23}$. The interictal spike/sharp are the hallmark of epilepsy, which demonstrates the cortical hyperexcitability and hypersynchrony, which may persists in the "normal" interictal state. The objective of our study was to determine the sensitivity and specificity of EEG among Bangladeshi patients with clinically suspected seizure events.

\section{Material and methods:}

This retrospective chart review was carried out in Electrophysiology Laboratory in Neurology Department of Dhaka Medical College Hospital, Dhaka, from January 2011 to December 2013. Our study population included 1154 epilepsy patients. Consultant neurologists took meticulous history along with proper physical examination in the lab. All the information was recorded in black and white. Our selection criteria included all the cases with convincing history of seizure events, which were sent for EEG and those with complete set of desired information in hospital recored. They were advised to wash hair with shampoo and not to sleep overnight. EEG was done within one to six months of seizure event. Each recording of EEG were obtained through digital equipments with minimal duration of 20-30 minutes and electrode positioned on scalp according to international 10-20 system. Recording was done in both awake and sleep state, except those who didn't sleep, only awakened state recording was taken. Provocative stimuli like hyperventilation, photic stimulation were given for three minutes each. For standardization, the background activity was classified as normal (organized and symmetrical) or abnormal (disorganized and/ or asymmetrical). The EEG was interpretated by consultant neurologist, trained and experienced in electro-physiologic studies. The EEG was examined for specific epileptiform abnormality, the interictal spike or sharp wave. The abnormal electroencephalographic activity was also classified as generalized or focal. The presence and topography of bursts of slow waves and epileptiform paroxysms were evaluated. The latter were classified as spike-wave, sharpwave and polyspike. EEG was done within one month of last seizure and mostly after a single event. Though a total of 1187 patients were initially included, 33 patients with marked artifacts on EEG were excluded from this study.

\section{Results:}

In our study, the patient's age ranged from birth to 75 years. The mean age at presentation to the EEG room was $17 \pm 11.4$ years i.e. most of the patients were less than 10 years old (44.4\%). About Three fourth of the patients $(72.9 \%)$ were aged less than 20 years. Only $3.7 \%$ were older than 50 years (Table-I). The male predominated in our study $(59.2 \%)$. Clinically diagnosed seizure was present in 970 patients $(84.1 \%)$. Generalized tonic clonic seizure (GTCS) was the most common clinical type of seizure encoured at the electrophysiology lab, followed by secondary generalized seizure in $19.4 \%(n=224)$ and focal seizure in $2 \%(n=30)$ patients. About $6.8 \%$ $(\mathrm{n}=79)$ patients had pseudoseizure (Table-II).

EEG was found to be normal in 473 patients (41\%). Among the abnormal EEG (59\%), generalized epileptiform discharge was found 
in $29 \%$, whereas focal and secondary generalized discharge was found in $30 \%$. The most common site of origin of epileptiform discharge was temporal lobe $(28.3 \%)$. The origin was hemispheric in $26.5 \%$, paracentric in $17.6 \%$ and Frontal in $9.24 \%$. We could not identify the site of origin in 63 patients $(18.2 \%)$ (Table-III).

The EEG was normal among 332 patients who had clinically confirmed seizure and was abnormal in 39 patients who did not have any clinical seizure event. The overall sensitivity of EEG was $66 \%$ (ranged from $62 \%$ to $68 \%$ with a confidence interval (CI) at 95\%) and specificity was $79 \%(72-84 \%$ at $95 \% \mathrm{CI})$. The positive predictive value was $58 \%(55-61 \%$ at $95 \% \mathrm{CI}$ ) and negative predictive value was $41 \%$ (38-44\% at 95\% CI) (Table-IV).
Table-I

Distribution of patients by age and sex $(n=1154)$

\begin{tabular}{lcc}
\hline Age Group (in years) & Number & Percentage \\
\hline$<10$ & 512 & 44.4 \\
$11-20$ & 239 & 28.5 \\
$21-30$ & 171 & 14.8 \\
$31-40$ & 65 & 5.6 \\
$41-50$ & 34 & 2.9 \\
$51-60$ & 23 & 2 \\
$>60$ & 20 & 1.7 \\
Sex & & \\
$\quad$ Male & 683 & 59.2 \\
$\quad$ Female & 471 & 40.8 \\
\hline
\end{tabular}

Table-II

Clinical seizure events $(n=1154)$

\begin{tabular}{llcc}
\hline Parameter & & Number & Percentage \\
\hline Seizure Event & & & \\
& Present & 970 & 84.1 \\
& Absent & 184 & 15.9 \\
Seizure Types & Focal & 30 & 2.6 \\
& Secondary Generalized & 224 & 19.4 \\
& Generalized & 641 & 55.5 \\
& Pseudo seizure & 75 & 6.7 \\
\hline
\end{tabular}

Table-III

Findings in EEG $(n=1154)$

\begin{tabular}{llcc}
\hline Findings & & Number & Percentage \\
\hline Normal & & 473 & 41 \\
Abnormal & GE & & \\
& LRE & 333 & 28.9 \\
& Site of epileptogenesis of LRE & 346 & \\
Temporal & 98 & \\
& Frontal & 32 & 28.3 \\
& Paracentral & 61 & 9.24 \\
& Hemispheric & 92 & 17.63 \\
& Undetermined & 63 & 26.5 \\
& & & 18.2 \\
\hline
\end{tabular}


Table-IV

Sensitivity and specificity of EEG $(n=1154)$

\begin{tabular}{llccccc}
\hline Test & \multicolumn{2}{c}{ Seizure Event } & & \\
& & & Total & Sensitivity & Specificity \\
\hline EEG & & Present & Absent & & $66 \%$ & $79 \%$ \\
& Normal & 332 & 145 & 477 & & \\
& Abnormal & 638 & 39 & 677 & \\
\hline
\end{tabular}

\section{Discussion:}

EEG is an old and established investigation. One may ask the rationale for conducting this study again in Bangladesh as there are many published reports regarding sensitivity and specificity of EEG. In most published series, patients having epileptiform discharges detected on an interictal EEG are significantly more likely to have another seizure than those with normal results on EEG. That means, there is a significant association between the presence of epileptiform discharges and a subsequent seizure ${ }^{24,25}$. But, the frequency of reported EEG abnormalities in patients with seizures varies widely between studies. The sensitivities of EEG range from 29 to $69 \%{ }^{26-29}$. In addition, when EEGs are repeated in the same subject, the results are often inconsistent ${ }^{30}$. Variations in reported test characteristics may be related to differences in patient characteristics or to differences in reader thresholds for interpreting tests as positive. Tests with wide interobserver or intersubject variability may yield inaccurate or uninterpretable results ${ }^{31}$. This variation from both the patients and observer side made us conducting the study in our own population.

The incidence of epilepsy varies with age. A number of studies report the incidence of epilepsy in specific age groups. These include studies of children, ${ }^{32-38}$ adults, ${ }^{39-41}$ and the elderly ${ }^{42,43}$. Contrary to popular belief, epilepsy is a disease with onset at the extremes of life, we found a higher proportion of patients under 10 years of age and the elderly being very small in number. This finding is also not inconsistent with other studies, where provided, age-specific incidence is consistently high in the youngest age groups, with highest incidence occurring during the first few months of life. Incidence falls dramatically after the first year of life, seems relatively stable through the first decade of life, and falls again during adolescence ${ }^{44-46}$. Seizure was also more frequent in male. In most total population studies, incidence of epilepsy or of unprovoked seizures is higher in males than in females. This seems true even after the higher incidence in males of definitive risk factors for epilepsy (i.e., head injury, stroke, central nervous system infection) is taken into account ${ }^{6-12,47,48}$. For most but not all incidence studies, sex-specific differences in incidence are not statistically significant. The consistency of the male-to-female difference across studies suggests that males are at higher risk than females for unprovoked seizures and epilepsy.

Seizure-specific incidence or proportions of cases with a specific seizure type based on the International Classification of Epileptic Seizures are provided in several contemporary incidence studies ${ }^{49-53}$. The frequency of both partial seizure and GTCS varied among different studies, which might account for the difference in methodological and geographical perspective. Granieri et $\mathrm{al}^{49}$, Olafsson et $\mathrm{al}^{51}$ and Tekle-Haimanot et $\mathrm{al}^{53}$ found a higher proportion of HTCS like our study. Studies on adult epilepsies showed that the chance of detecting interictal epileptiform discharges (IEDs) from the first EEG varies between 29\% and 55\%54-56. A Repeat EEG may ultimately demonstrated the IEDs in $80 \%-90 \%$ of the patients ${ }^{54,56}$. We had a similar yield of abnormal report in EEG. There is wide variation in sensitivity (23\%-77\%) and specificity (24\%-99\%) of reported EEG in general population ${ }^{58-67}$. Donald L et $\mathrm{al}^{68}$ concluded three important 
findings related to wide variation in sensitivity and specificity of EEG. "The first is that the sensitivity and specificity of EEG varies widely among published studies. The second finding is that a large proportion of this variance appears to be accounted for by the interpretation threshold of the neurologist readers. The third finding is that there is an uneven trade-off between specificity and sensitivity in EEG interpretations. Higher specificity readers had greater diagnostic accuracy in predicting seizure recurrence than did higher sensitivity readers". We found a higher specificity than sensitivity of EEG. The positive predictive value of EEG as a diagnostic test was also higher than the negative predictive value.

Some individuals who do not have epilepsy may have interictal discharges (IED). The probability that an IED indicates epilepsy relates to the location of the discharge. Only about $40 \%$ of individuals with central-mid-temporal spikes and $50 \%$ of those with occipital spikes have seizures ${ }^{69-71}$. A photoparoxysmal response and generalized spike-wave discharges are often found in asymptomatic individuals, who may carry the genetic trait for spike-wave discharges, but lack the susceptibility of seizure, which might be the explanation of these negative EEG. The photoparoxysmal response accounts for 63\% of IEDs found in subjects without epilepsy, who are not apt to develop seizures later in life ${ }^{69,72-74}$. In contrast, people with midline, anterior temporal, midtemporal, and multifocal spikes usually have epilepsy; up to $90-95 \%$ of these individuals have epilepsy69,72.

\section{Conclusion:}

Even though the diagnosis of epilepsy is clinical and based mostly on the acquisition of correct history, the EEG remains a key supportive investigation with a reasonable sensitivity and specificity. One interesting observation in our study was that it had higher specificity than sensitivity which may suggest that a patient with a negative EEG is less likely to have a seizure event.

\section{References:}

1. Gibbs FA, Davis H, Lennox WB. The electroencephalogram in epilepsy and in conditions of impaired consciousness. Arch Neurol Psychiatry 1935; 34: 1133-48.

2. Allen CMC, Lueck CJ, Dennis M. Neurologic disease. In: Colledge NR, Walker BR, Ralston SH, eds. Davidson's Principles and Practice of Medicine. $21^{\text {st }}$ edn. Elsevier Limited; 2010: pp1172 .

3. Yacubian EMT. Epilepsia: o conceito atual. In: Yacubian EMT, editor. Epilepsia da Antiguidade ao Segundo Milênio. São Paulo: Lemos; 2000. p. 82-8.

4. Commission on Tropical Diseases of the International League Against Epilepsy. Relationship between epilepsy and tropical diseases. Epilepsia 1994; 35: 89-93.

5. Burneo JG, Tellez-Zenteno J, Wiebe $\mathrm{S}$. Understanding the burden of epilepsy in Latin America: a systematic review of its prevalence and incidence. Epilepsy Res 2005; 66: 63-74.

6. Preux PM, Druet-Cabanac M. Epidemiology of epilepsy in sub- Saharan Africa. Lancet Neurol 2005; 4: 21-31.

7. Li SC, Schoenberg BS, Wang CC, et al. Epidemiology of epilepsy in urban areas of the People's Republic of China. Epilepsia 1985; 26: 391-4.

8. Fong GCY, Mak W, Cheng TS, et al. A prevalence study of epilepsy in Hong Kong. Hong Kong Med J 2003; 9: 252-7.

9. Bharucha NE. Epidemiology of epilepsy in India. Epilepsia 2003; 44: 9-11.

10. Murthy JMK, Vijay S, Ravi Raju C, et al. Acute symptomatic seizures associated with neurocysticercosis: A community-based prevalence study and comprehensive rural epilepsy study in South India. Neurol Asia 2004; 9: 86.

11. Rajbhandari KC. Epilepsy in Nepal. Neurol J Southeast Asia 2003; 8: 1-4.

12. Aziz H, Ali SM, Frances P, et al. Epilepsy in Pakistan: a community based epidemiologic study. Epilepsia 1994; 35: 950-8.

13. Su CL, Chang SF, Chen ZY, et al. Prevalence of epilepsy in Ilan, Taiwan. Taiwan Epileps Soc Bull 1997; 7: 47.

14. Asawavichienjinda T, Sitthi-Amorn C, Tanyanont W. Prevalence of epilepsy in rural Thailand: a population-based study. J Med Assoc Thai 2002; 85: 1066-73. 
15. Aziz H, Guvener A, Akhtar SW, et al. Comparative epidemiology of epilepsy in Pakistan and Turkey: population based studies using identical protocols. Epilepsia 1997; 38: 716-22.

16. WHO report on Epilepsy in South East Asia. Some facts and figures in Epilepsy. Avaialable at: http:/ /www.searo.who.int/LinkFiles / Information and_Documents_facts.

17. Berg AT, Shinnar S. The risk of seizure recurrence following a first unprovoked seizure: a quantitative review. Neurology 1991; 41: 965-72.

18. Berg AT, Shinnar S. Relapse following discontinuation of antiepileptic drugs: a metaanalysis. Neurology 1994; 44: 601-8.

19. Goodin DS, Aminoff MJ. Does the interictal EEG have a role in the diagnosis of epilepsy? Lancet 1984; 1: 837-9.

20. Binnie CD, Stefan H. Modern electroencephalography: its role in epilepsy management. Clin Neurophysiol 1999; 110: 16797.

21. Iida N, Okada S, Tsuboi T. EEG abnormalities in nonepileptic patients. Folia Psychiatr Neurol Jpn 1985; 39: 43-58.

22. Camfield P, Gordon K, Camfield C, Tibbles J, Dooley J, Smith B. EEG results are rarely the same if repeated within six months in childhood epilepsy. Can J Neurol Sci 1995; 22: 297-300.

23. Andersson T, Braathen G, Persson A, Theorell K. A comparison between one and three years of treatment in uncomplicated childhood epilepsy: a prospective study. II. The EEG as predictor of outcome after withdrawal of treatment. Epilepsia 1997; 38: 225-32.

24. Berg AT, Shinnar S. The risk of seizure recurrence following a first unprovoked seizure: a quantitative review. Neurology 1991; 41: 965-72.

25. Berg AT, Shinnar S. Relapse following discontinuation of antiepileptic drugs: a metaanalysis. Neurology 1994; 44: 601-8.

26. Salinsky M, Kanter R, Dasheiff RM. Effectiveness of multiple EEGs in supporting the diagnosis of epilepsy: an operational curve. Epilepsia 1987; 28: 331-4.

27. Goodin DS, Aminoff MJ. Does the interictal EEG have a role in the diagnosis of epilepsy? Lancet 1984; 1: 837-9.

28. Binnie CD, Stefan H. Modern electroencephalography: its role in epilepsy management. Clin Neurophysiol 1999; 110: 167-97.

29. Iida N, Okada S, Tsuboi T. EEG abnormalities in nonepileptic patients. Folia Psychiatr Neurol Jpn 1985; 39: 43-58.
30. Camfield P, Gordon K, Camfield C, Tibbles J, Dooley J, Smith B. EEG results are rarely the same if repeated within six months in childhood epilepsy. Can J Neurol Sci 1995; 22: 297-300.

31. Deeks JJ. Systematic reviews in health care: systematic reviews of evaluations of diagnostic and screening tests. BMJ 2001; 323: 157-62.

32. Beilmann A, Napa A, Hamarik M, et al. Incidence of childhood epilepsy inmEstonia. Brain Dev 1999; 21(3): 166-74.

33. Benna P, Ferrero P, Bianco $\mathrm{C}$, et al. Epidemiological aspects of epilepsy in the children of a Piedmontese district (Alba-Bra). Panminerva Med 1984; 26(2): 113-8.

34. Doose H, Sitepu B. Childhood epilepsy in a German city. Neuropediatrics 1983; 14(4): 220-4.

35. Ellenberg JH, Hirtz DG, Nelson KB. Age at onset of seizures in young children. Ann Neurol 1984; 15(2): 127-34.

36. Freitag CM, May TW, Pfafflin M, et al. Incidence of epilepsies and epileptic syndromes in children and adolescents: a population-based prospective study in Germany. Epilepsia 2001; 42(8): 97985.

37. Shamansky SL, Glaser GH. Socioeconomic characteristics of childhood seizure disorders in theNew Haven area: an epidemiologic study. Epilepsia 1979; 20(5): 457-74.

38. Sidenvall R, Forsgren L, Blomquist HK, et al. A community-based prospective incidence study of epileptic seizures in children. Acta Paediatr 1993; 82(1): $60-5$.

39. Keranen T, Riekkinen PJ, SillanpaaM. Incidence and prevalence of epilepsy in adults in eastern Finland. Epilepsia 1989; 30(4): 413-21.

40. Hauser WA, Annegers JF, Kurland LT. Incidence of epilepsy and unprovoked seizures in Rochester, Minnesota: 1935-1984. Epilepsia 1993; 34(3): 453-68.

41. Forsgren L, Bucht G, Eriksson S, et al. Incidence and clinical characterization of unprovoked seizures in adults: a prospective population-based study. Epilepsia 1996; 37(3): 224-9.

42. Luhdorf K, Jensen LK, Plesner AM. Epilepsy in the elderly: incidence, social function, and disability. Epilepsia 1986; 27(2): 135-41.

43. Loiseau J, Loiseau P, Duche B, et al. A survey of epileptic disorders in southwest France: seizures in elderly patients. Ann Neurol 1990; 27(3): 2327 .

44. Camfield CS, Camfield PR, Gordon K, et al. Incidence of epilepsy in childhood and adolescence: a population-based study in Nova 
Scotia from 1977 to 1985 . Epilepsia 1996; 37(1): 19-23.

45. HauserWA, Annegers JF, RoccaWA. Descriptive epidemiology of epilepsy: contributions of population-based studies from Rochester, Minnesota. Mayo Clin Proc 1996; 71(6): 576-86.

46. Olafsson E, Ludvigsson P, Gudmundsson G, et al. Incidence of unprovoked seizures and epilepsy in Iceland and assessment of the epilepsy syndrome classification: a prospective study. Lancet Neurol 2005; 4(10): 627-34.

47. Al Rajeh S, Awada A, Bademosi O, et al. The prevalence of epilepsy and other seizure disorders in an Arab population: a community-based study. Seizure 2001; 10(6): 410-4.

48. Annegers JF, Dubinsky S, Coan SP, et al. The incidence of epilepsy and unprovoked seizures in multiethnic, urban health maintenance organizations. Epilepsia 1999; 40(4): 502-6.

49. Granieri E, Rosati G, Tola R, et al. A descriptive study of epilepsy in the district of Copparo, Italy, 1964-1978. Epilepsia 1983; 24(4): 502-14.

50. Joensen P. Prevalence, incidence, and classification of epilepsy in the Faroes. Acta Neurol Scand 1986; 74(2): 150-5.

51. Olafsson E, Hauser WA, Ludvigsson P, et al. Incidence of epilepsy in rural Iceland: a population-based study. Epilepsia 1996; 37(10): 951-4.

52. Rwiza HT, Kilonzo GP, Haule J, et al. Prevalence and incidence of epilepsy in Ulanga, a rural Tanzanian district: a community-based study. Epilepsia 1992; 33(6): 1051-6.

53. Tekle-Haimanot R, Forsgren L, Ekstedt J. Incidence of epilepsy in rural central Ethiopia. Epilepsia 1997; 38(5): 541-6.

54. Marsan CA, Zivin LS. Factors related to the occurrence of typical paroxysmal abnormalities in the EEG records of epileptic patients. Epilepsia 1970; 11: 361-81.

55. Goodin DS, Aminoff MJ, Laxer KD. Detection of epileptiform activity by different noninvasive EEG methods in complex partial epilepsy. Ann Neurol 1990; 27: 330-4.

56. Salinsky M, Kanter R, Dasheiff RM. Effectiveness of multiple EEGs in supporting the diagnosis of epilepsy: an operational curve. Epilepsia 1987; 28: 331-4.

57. Boulloche J, Leloup P, Mallet E, Parain D, Tron P. Risk of recurrence after a single, unprovoked, generalized tonic-clonic seizure. Dev Med Child Neurol 1989; 31: 626-32.

58. Camfield PR, Camfield CS, Dooley JM, Tibbles JA, Fung T, Garner B. Epilepsy after a first unprovoked seizure in childhood. Neurology 1985; 35: $1657-60$.

59. Hopkins A, Garman A, Clarke C. The first seizure in adult life: value of clinical features, electroencephalography, and computerised tomographic scanning in prediction of seizure recurrence. Lancet 1988; 1: 721-6.

60. Shinnar S, Berg AT, Moshe SL, et al. The risk of seizure recurrence after a first unprovoked afebrile seizure in childhood: an extended follow-up. Pediatrics 1996; 98: 216-25.

61. Stroink H, Brouwer OF, Arts WF, Geerts AT, Peters AC, van Donselaar CA. The first unprovoked, untreated seizure in childhood: a hospital based study of the accuracy of the diagnosis, rate of recurrence, and long term outcome after recurrence. Dutch study of epilepsy in childhood. J Neurol Neurosurg Psychiatry 1998; 64: 595-600.

62. Cleland PG, Mosquera I, Steward WP, Foster JB. Prognosis of isolated seizures in adult life. Br Med J (Clin Res Ed) 1981; 283: 1364.

63. Ramos Lizana J, Cassinello Garcia E, Carrasco Marina LL, Vazquez Lopez M, Martin Gonzalez M, Munoz Hoyos A. Seizure recurrence after a first unprovoked seizure in childhood: a prospective study. Epilepsia 2000; 41: 1005-13.

64. Dooley J, Gordon K, Camfield P, Camfield C, Smith E. Discontinuation of anticonvulsant therapy in children free of seizures for 1 year: a prospective study. Neurology 1996; 46: 969-74.

65. Emerson R, D'Souza BJ, Vining EP, Holden KR, Mellits ED, Freeman JM. Stopping medication in children with epilepsy: predictors of outcome. N Engl J Med 1981; 304: 1125-9.

66. Holowach J, Thurston DL, O'Leary J. Prognosis in childhood epilepsy. Follow-up study of 148 cases in which therapy had been suspended after prolonged anticonvulsant control. N Engl J Med 1972; 286: 169-74.

67. Shinnar S, Vining EP, Mellits ED, et al. Discontinuing antiepileptic medication in children with epilepsy after two years without seizures. A prospective study. N Engl J Med 1985; 313: 976-80.

68. Donald L. Gilbert, MD; Gopalan Sethuraman, $\mathrm{PhD}$; Uma Kotagal, MBBS; and C. Ralph Buncher, ScD. Meta-analysis of EEG test performance shows wide variation among studies. Neurology 2002; 60: $564-70$.

69. Bridgers SL. Epileptiform abnormalities discovered on electroencephalographic screening of psychiatric inpatients. Arch Neurol 1987; 44: 312-6. 
70. Kellaway P. The incidence, significance, and natural history of spike foci in children. In: Henry $\mathrm{CE}$, ed. Current clinical neurophysiology: update on EEG and evoked potentials. Amsterdam: Elsevier; 1981. p. 151-75.

71. Ehle A, Co S, Jones MG. Clinical correlates of midline spikes. An analysis of 21 patients. Arch Neurol 1981; 38: 355-7.

72. Metrakos JD, Metrakos K, eds. Genetic factors in the epilepsies. NINDS Monograph No. 14 ed.Washigton, D.C.: US Government Printing
Office; 1972. Alter M, HauserWA, eds. The epidemiology of epilepsy: a workshop.

73. Gregory RP, Oates T, Merry RT. Electroencephalogram epileptiform abnormalities in candidates for aircrew training. Electroencephalogr Clin Neurophysiol 1993; 86: 75-7.

74. Scollo-Lavizzari C. Prognostic significance of epileptiform discharges in the EEG of nonepileptic subjects during photic stimulation [abstract]. Electroencephalogr Clin Neurophysiol 1971; 31: 174. 